\title{
Haemangiopericytoma of the stomach
}

\author{
G. N. MARANGOS \\ From the General Hospital, Nicosia, Cyprus
}

\begin{abstract}
EDITORIAL SYNOPSIS The case is reported of a woman aged 40, from whom a haemangiopericytoma of the stomach was removed by partial gastrectomy. No metastases were found and the patient remains well 15 months after operation. The histological and clinical features of such gastric tumours are discussed. Whereas $21 \%$ of histologically similar tumours arising in other parts of the body have proved malignant, no evidence of malignancy has been encountered among the small number of gastric haemangiopericytomata so far recorded.
\end{abstract}

Among the rarer tumours of the stomach, that designated by Stout and Murray (1942) as haemangiopericytoma deserves special interest since very few examples have been reported and its natural history is consequently ill understood. The present case is therefore considered worthy of record.

\section{CASE REPORT}

An otherwise healthy woman of 40 years was referred to the Nicosia General Hospital on 30 October 1962 because of severe melaena and haematemesis. During the previous five months she had suffered from epigastric pains unrelated to food, and from progressive weakness. Her earlier history was irrelevant. Clinically the only abnormality was anaemia ( $\mathrm{Hb} 53 \%$ ). Occult blood was present in the stools. Barium meal revealed a large filling defect on the lesser curvature of the stomach. The appearances were considered to be those of a gastric tumour, most probably malignant.

At operation the stomach was found to be slightly enlarged and its wall hypertrophied. Two fingerbreadths above the pylorus was a tumour the size of a small banana lying partly within and partly without the stomach, whose wall it did not appear to have infiltrated. No enlarged lymph nodes or other evidence of metastasis was found, nor any pathology of the other abdominal viscera. Although the appearance of the tumour was highly suggestive of a benign nature, it was thought inadvisable to remove only the mass; instead a typical gastric threequarter resection was performed. The patient made a normal post-operative recovery.

The excised specimen was opened along the greater curvature. On the lesser curve, two fingerbreadths above the pylorus, the wall of the stomach enclosed a solid tumour the size and shape of a banana covered by apparently intact gastric mucosa. On transection the tumour had a greyish surface (Fig. 1).

Five blocks from the tumour were submitted to histological examination (Dr. G. A. K. Missen). Sections showed a tumour lying (block A) in the submucosa of the stomach and separated from the overlying muscularis mucosae by a thin layer of collagen. The overlying mucosa appeared within normal limits for the junction of body of stomach and pyloric antrum. Sections of another block showed loss of the overlying gastric mucosa in one area, with necrosis and polymorph infiltration of the denuded superficial layer of tumour tissue. The tumour contained large numbers of small blood vessels, many of which were surrounded in onion-skin fashion by a broad cuff of concentrically-arranged slender fusiform cells (Figs. 2, 3) whose cytoplasm was picrophil with van Gieson's stain and was coloured a dull bluish-grey by Mallory's phosphotungstic acid-haematoxylin. They were separated from one another by concentrically-arranged reticulin fibres surrounding the vessels (Fig. 4). The intervening tissue was made up of large numbers of similar cells lying in a stroma of reticulin with very little collagen, and usually roughly arranged in the form of interwoven parallel bundles. Here and there were a few spindle-shaped cells with plumper nuclei, which were probably fibroblasts. No mitotic activity was seen. The tumour was lightly infiltrated throughout by eosinophil leucocytes and a few plasma cells. It was concluded that this was a very well-differentiated haemangiopericytoma, and its very close histological resemblance to the gastric

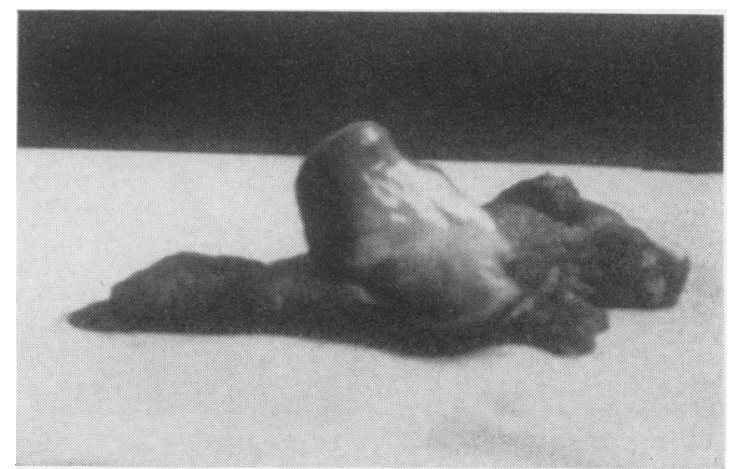

FIG. 1. Haemangiopericytoma of the stomach: solid tumour the size and shape of a banana on the lesser curve. 


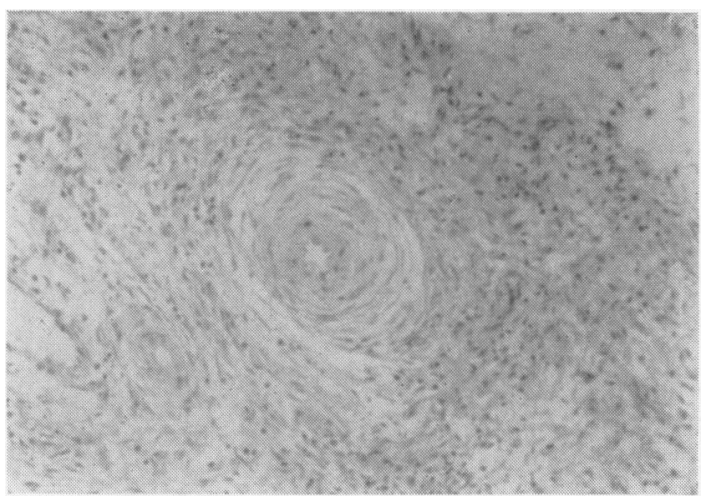

FIG. 2. Medium-power photomicrograph of a representative part of the tumour showing (centre) a blood vessel cut in transverse section enclosed by concentrically disposed pericytes arranged in onion-skin fashion. Haematoxylin and eosin $\times 39$.

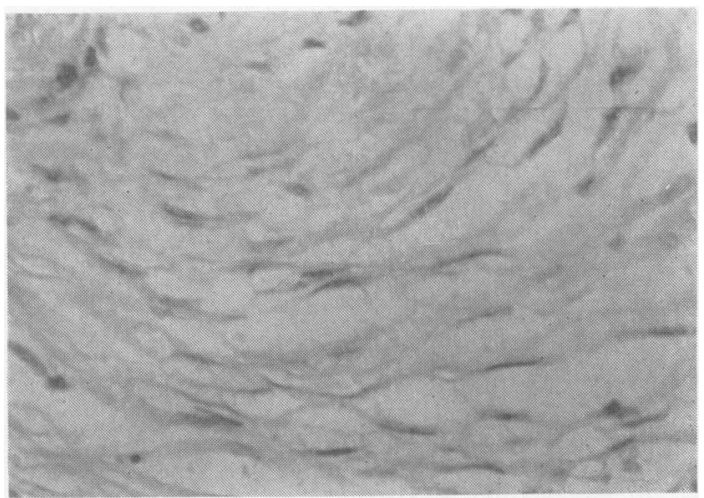

FIG. 3. High-power photomicrographs of the tumour showing slender pericytes surrounding a blood vessel, which is partly visible at the top right. Haematoxylin and eosin $\times 160$.

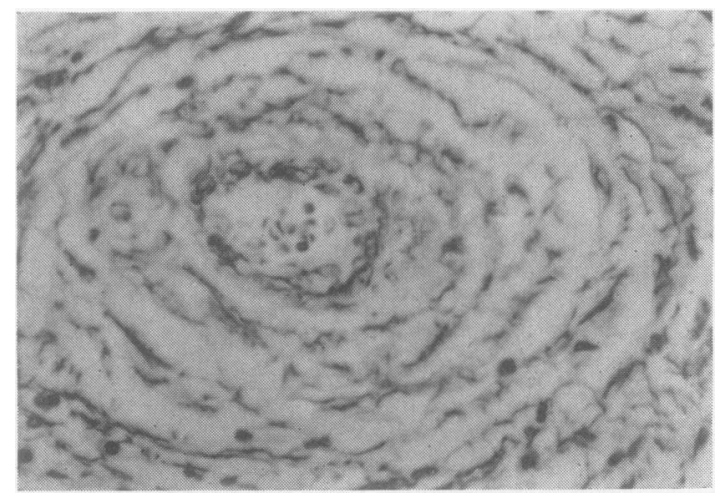

FIG. 4. High-power photomicrograph showing the characteristic concentric arrangement of reticulin fibres surrounding a blood vessel in the tumour. Haematoxylin and carmalum $\times 160$. haemangiopericytoma illustrated by Stout (1953) was remarked upon.

At the time of writing, 15 months after operation, the patient enjoys perfect health.

\section{DISCUSSION}

In 1942 Stout and Murray published a study of nine tumours for which they suggested the name of haemangiopericytoma. Later, in 1949, Stout reported some additional cases. The anatomical distribution of these tumours is very wide and they are found wherever capillaries are found. The majority occur in subcutaneous or muscular layers, and such tumours have been reported in the head, neck, upper and lower extremities, in the retroperitoneal, mesenteric and omental tissues, orbit, tongue, pericardium, pleura, ileum, and meninges. By 1953, Stout had encountered four examples arising in the wall of the stomach, as in the present case. From their histology it is evident that these gastric tumours are derived from vessels, for they consist of numerous small vascular channels, obvious or occult, surrounded by enclosing masses of spindle-shaped or round cells which Stout and Murray (1942) identified as possibly the pericytes of Zimmermann (1923). The tumours are usually firm, circumscribed, and often nodular; the cystic example published by Liaras and Laffargue (1956) was exceptional. Marked vascularity of the tumours or their immediate surroundings is not evident to the naked eye.

Zolotas and Pappis (1963), in reporting a case of gastric haemangiopericytoma, cited seven others which had been published or referred to in the literature since this entity was first described (Liaras and Laffargue, 1956; Farber, Bandler, and Mackles, 1957; Cohen, Yesner, and Spiro, 1959; Badon and Bonneau, 1960; Van Der Voort, 1960; De Busscher, 1961; and Le Cluyse, 1961). Since, however, the differential diagnosis of haemangiopericytoma from other rare tumours of the stomach, such as glomus tumour and haemangio-endothelioma, is not an easy one, it is possible that some examples may have been reported under another name. There is not complete unanimity as to the origin and the classification of these tumours, and some authors (e.g., Helwig and Ranier, 1953; Cohen et al., 1959), relying on the existence of a granular hyperplasia of the overlying mucosa and the infiltration throughout with eosinophil leucocytes, consider them to be inflammatory in nature, and to result probably from an allergic reaction. The macroscopic and histological appearances in our case do not admit of such an interpretation.

The published examples of gastric haemangiopericytoma have varied in size from that of a cherry 
to that of a baby's head; they were equally distributed between men and women, and the age of the patients was between 46 and 72 years. While the speed of their growth is not known, their clinical histories would suggest that it is probably to be measured in months and seldom more than three years, in contrast to the omental tumour reported by Stout and Cassel (1943) which was known to have been present for at least 60 years and possibly more. (Other extragastric cases from Stout and Murray (1942) were of long duration, e.g., 15, 24, 31, and 38 years.) The symptoms to which the gastric tumours give rise are variable and may be atypical. In some cases there was slight epigastric pain unrelated to food, but in most there were no symptoms relating to the epigastrium. The most prominent feature is repeated bleeding manifest as haematemesis or melaena, the only sign in $43 \%$ of the operated cases. This, together with the invariable radiological findings of either a polypoid tumour or an interruption of the gastric mucosa in the region of the antrum, constitutes the main help in diagnosis and the usual indication for operation.

In the 12 recorded cases of gastric haemangiopericytoma which came to operation no metastasis or other evidence of malignancy was found, despite the fact that Stout speaks of a $21 \%$ rate of malignant degeneration and metastasis in his extragastric cases. (Metastases were found in the liver in Stout's (1949) case of haemangiopericytoma of the ileum.) In the case reported by Stout (1953), which is so similar to ours, the patient showed no evidence of metastasis five years after partial gastrectomy. The prognosis of gastric haemangiopericytoma would thus appear to be considerably better than that of similar tumours arising elsewhere.
Of the 12 cases reported, four had local removal of the tumour and the remaining eight partial gastrectomy. The surgeon encountering such an unusual tumour of the stomach may well be uncertain of its nature, in which case a partial gastrectomy is advisable. In rare instances, however, as in the case of Liaras and Laffargue (1956) where diagnosis was established by frozen section, local excision has been carried out with success.

I would like to thank Dr. G. A. K. Missen of the Department of Pathology, Guy's Hospital, London, for the pathological report and the photomicrographs.

\section{REFERENCES}

Badon, A., and Bonneau, H. (1960). Un cas d'hémangiopéricytome de l'estomac. Arch. Mal. Appar. dig., 49, 1750.

Cohen, N., Yesner, R., and Spiro, H. M. (1959). Inflammatory fibroid polyp ("Hemangiopericytoma") of the stomach. Amer. J. dig. Dis., N.S. 4, 549.

De Busscher, G. (1961). See Le Cluyse (1961). Discussion.

Farber, M., Bandler, M., and Mackles, A. (1957). Hemangiopericytoma of the stomach. Gastroenterology, 33, 503.

Helwig, E. B., and Ranier, A. (1953). Inflammatory fibroid polyps of the stomach. Surg. Gynec. Obstet., 96, 355.

Le Cluyse, R. (1961). Hémangiopericytome de l'estomac. Acta gastro-ent. belg., $24^{1}, 583$.

Liaras and Laffargue (1956). Un cas d'hémangio-péricytome de la paroi gastrique. Mém. Acad. Chir., 82, 256.

Stout, A. P. (1949). Hemangiopericytoma: a study of twenty-five new cases. $C A(N . Y), 2,1027$.

- - (1953). Atlas of Tumor Pathology, Section VI, Fascicle 21, Tumors of the stomach, pp. 36-39, 46. Armed Forces Institute of Pathology, Washington, D.C.

- - and Cassel, C. (1943). Hemangiopericytoma of the omentum. Surgery, 13, 578.

— and Murray, Margaret R. (1942). Hemangiopericytoma: a vascular tumor featuring Zimmerman's pericytes. Ann. Surg., 116, 26.

Van Der Voort, G. (1960). L'hémangiopéricytome gastrique. Acta chir. belg., 59, 755.

Zimmermann, K. W. (1923). Der feinere bau der Blutcapillaren. Ztschr. Anat. Entwickl. Gesch., 68, 29.

Zolotas, E., and Pappis, C. (1963). Hemangiopericytoma of the stomach. Hellen. Cheir., 10, 146. 